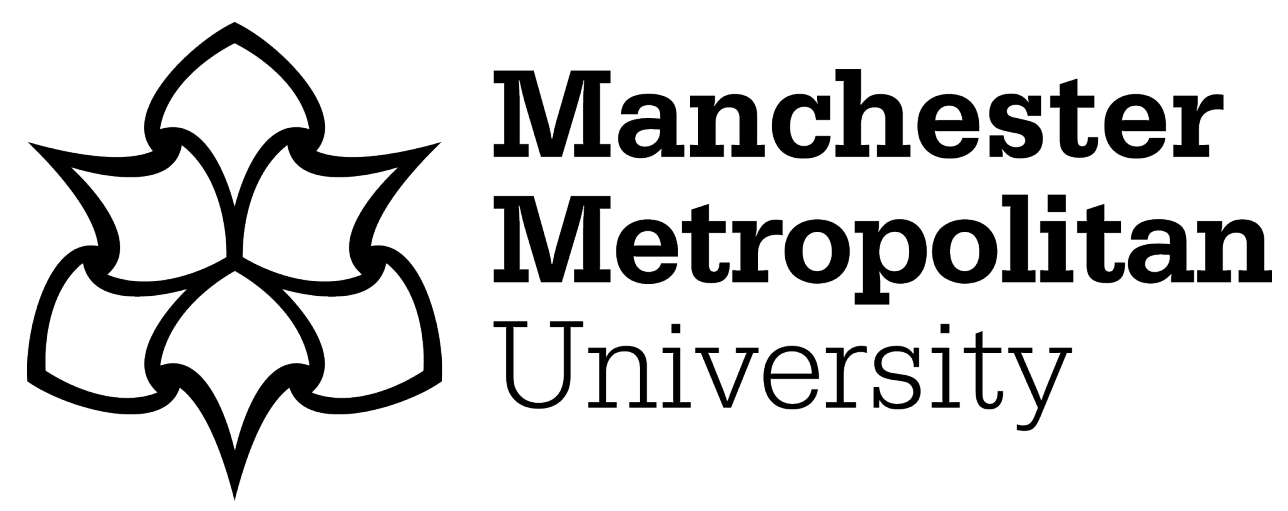

Giovanis, E and Ozdamar, O (2016) The impact of air pollution on health problems in Britain. International Journal of Sustainable Economy, 8 (2). pp. 163-186. ISSN 1756-5804

Downloaded from: https://e-space.mmu.ac.uk/620959/

Publisher: Inderscience

DOI: https://doi.org/10.1504/IJSE.2016.075904

Please cite the published version 


\title{
The impact of air pollution on health problems in Britain
}

\section{Eleftherios Giovanis}

University of Verona, Department of Economics, Vicolo Campofiore, 2, 37129, Italy

Email: giovanis95@gmail.com and eleftherios.giovanis@univr.it

\section{Oznur Ozdamar}

1. Adnan Menderes University, Aydın Faculty of Economics, Department of

Econometrics, Merkez Kampüsü, Aytepe Mevkii, 09010 Aydın, Turkey

2. Bologna University, Department of Economics, Strada Maggiore 45, 40125, Bologna, Italy

Email: oznur.ozdamar@adu.edu.tr and oznur.ozdamar@unibo.it

\begin{abstract}
This study explores the effects of air pollution on specific diseases and specifically skin conditions and allergy, chest and breathing and heart problems. The analysis is based on data derived by the British Household Panel Survey (BHPS), which is a panel dataset in United Kingdom during the period 1991-2009. Moreover, this study explores the willingness to pay for improving the air quality in the UK using data from the British Household Panel Survey (BHPS). In particular, two air pollutants are examined; ground-level ozone $\left(\mathrm{O}_{3}\right)$ and carbon monoxide (CO). Regarding the skin conditions and allergy health problems the annual monetary values for $\mathrm{O}_{3}$ range between $£ 45-£ 65$ per year for a drop of one unit, while the respective values for the $\mathrm{CO}$ range between $£ 70-£ 87$. The respective values for $\mathrm{O}_{3}$ and $\mathrm{CO}$ range between $£ 173-£ 218$ for chest and breathing health problems and $£ 178-£ 216$ and $£ 189-£ 222$ for heart problems.
\end{abstract}

Keywords: Air pollution; British Household Panel Survey; Environmental valuation; Health Diseases; Hospitalization Cost 


\section{Biographical Note}

Eleftherios Giovanis studied economics at the University of Thessaly. He completed the M.Sc. in applied economics and finance at the University of Macedonia, Greece and a second M.Sc. in quality assurance at the Hellenic Open University in Patra, Greece in 2009. He worked as statistician and econometrician analyst is marketing research companies. In December of 2014 he completed his Ph.d. in economics at Royal Holloway University of London. In 2013-2014 he worked as research collaborator in IMT Institute of Advanced Studies in Lucca, Italy, while currently now is individual Marie Sklodowska-Curie Research Fellow at University of Verona.

Oznur Ozdamar is assistant professor in the Department of Econometrics at Aydin Faculty of Economics of Adnan Menderes University and a researcher at Bologna University/Department of Economics working on a project entitled The Causal Effect of Air Pollution on Infant Health Outcomes Using The London Congestion Charge Policy. During the period 2014-2015 she worked as post-doctoral researcher at University of Bologna in the project entitled 'The Effects of Social Policies and Environmental Factors on Health Status and Health Problems: A Case Study of EU and Turkey". She studied economics and got her Ph.D. from IMT Institute for Advanced Studies in Italy. During her Ph.D., she was research fellow at Northwestern University in USA. 


\section{Introduction}

It is well emphasized in the relevant literature that air pollution significantly reduces life expectancy, causes additional admissions to hospitals and has harmful effects on the natural habitat. Chronic exposure to air pollution is the main reason of important health problems such as cardiovascular diseases and lung cancer. Moreover, air pollution can damage plants and animals in both aquatic and terrene ecosystem with vital impacts on biodiversity (DEFRA 2010). Furthermore, the valuation of the environment and air pollution is very important for health. However, policies to reduce pollution are often hardly implemented due to their excessive financial costs and thus it is crucial to estimate well the public willingness to pay for a cleaner environment.

The purpose of this study is to examine the determinants on specific health problems as skin, cardiovascular and respiratory system diseases using the British Household Panel Survey (BHPS) during the period 1991-2009. The analysis relies on detailed micro-level data, using local authority districts, instead of using counties like other studies do (Luechinger 2009; 2010; Ferreira et al., 2013). The advantage of using local authority districts is that it is possible to map the air pollution emissions at a detailed geographical reference implying more precise and robust estimates.

Firstly we start with an individual level binary Logit discrete choice fixed effect model. Secondly, a Probit dynamic binary model is applied. There are several key advantages of using these estimates. Firstly it is possible to control for the local authority district-specific, time invariant characteristics, as well as, using dynamic models it is possible to control to a large extent for many omitted variables. Additionally, two major air pollutants are explored, ozone $\left(\mathrm{O}_{3}\right)$ and carbon monoxide $(\mathrm{CO})$, as these are considered some of the most dangerous air pollutants. ${ }^{\mathrm{i}}$

Based on the data this paper relies on an approach which is similar to the life satisfaction evaluation (LSE). The limitations of this study are coming from the LSE approach, where it is possible that people choose where they live. This would bias the air pollution variable's coefficient downwards as those least resilient to air pollution would choose to reside in areas with cleaner air 
(Frey et al., 2010). Even though both non-movers and movers samples are examined, the population of interest is limited to non-movers in order to reduce endogeneity, which is discussed in the methodology section. Another limitation of this study is the usage of the BHPS and its panel structure where the typical panel data problems like attrition and non-response are common. On the other hand, in the panel datasets the same individuals are followed over time and thus their history is known and their inclusion in a fixed effects model is feasible.

The paper is organized as follows. Section 2 presents a short literature review. Section 3 describes the methodology followed, while in section 4 the data and the research sample design are provided. In section 5 the results of estimating the effects of air pollution on health diseases are reported and discussed. In section 6 the concluding remarks are presented.

\section{Literature Review}

Gerking and Stanley (1986)'s study can be taken into account as one of the first examples of a MWTP application regarding the relationship between air pollution and health. The authors used the St. Louis survey, in which the main activity of the individuals recorded as employed, was conducted over the period 1977-1980. The findings show that the annual willingness to pay estimates for a $30 \%$ reduction in ambient mean ozone concentrations, range from $\$ 18.45$ to $\$ 24.48$. Chay and Greenstone (2003) explored the air quality improvements induced by the Clean Air Act Amendments (CAAAs) of 1970 to estimate the causal impact of particulates pollution on infant mortality during period 19711972. The authors find that one per cent decline in TSP results in 0.5 per cent decline in the infant mortality rate.

Dockery et al. (1993) pointed out several air pollutants, especially fine particulate matter $\mathrm{PM}_{2}$, as the reasons of death from cancer and cardiopulmonary disease. Following him, many other studies in the literature on the health effects of air pollutants have been carried out for its adverse effects on physiological functions, subclinical symptoms and clinical diseases such as asthma, stroke, lung cancer and relevant deaths (Delfino et al. 1998; Wilhelm and Ritz 2003; O’Neill et al. 2004). 
On the other hand Currie and Neidell (2005), using the California Birth Cohort files and the California Ambient Air Quality Data at individual level during period 1989-2000, suggest an identification strategy which exploits within-zip code-month variation in pollution levels and creates measures of pollution at the zip code-week level and controls for individual differences between mothers that may be associated with variation in birth outcomes. After including the mother's zip code in the model, the authors report little average effect of prenatal pollution exposure on the probability of low birth weight, short gestation and fetal death. However, their findings suggest that residing in a highly polluted area is related to a higher risk of fetal death, showing that pollution may have harmful effects above a certain threshold level.

Also a number of epidemiological studies support for the respiratory effects of the traffic-related pollutants. For instance Shima et al. 2003 and Ostro et al. 2006 show that people in Japan residing close to main roads, where such a heavy traffic occurs, suffer more respiratory symptoms and allergies than those living further away. Similar studies carried out in other countries, like the UK, the USA and in the Netherlands (Oosterlee et al., 1996; Van Vliet et al., 1997; McConnell et al., 2006) pointing out the high traffic intensity as the reason of increased respiratory symptoms and reduced lung function in children due to the levels of particulate matter in the air.

Previous studies also emphasize on the importance of social and economic determinants for individuals' health. The Self-Assessed Health (SAH) has been widely used in prior British case studies of the relationship between health and socioeconomic status (Benzeval et al. 2000; Adams et al. 2003; Contoyannis et al. 2004) and of the relationship between health and lifestyles (Contoyannis and Jones 2004). The results of those studies are various and they suggest that socioeconomic characteristics and lifestyle are significantly associated with health. More specifically, previous findings support that employed, higher educated individuals and married are more likely to present higher levels of health status, than the unemployed, less educated individuals and those who are widowed and divorced. 
Regarding the weather effects former studies revealed significant effect of weather on health status and well-being. Temperature-mortality research has mostly concentrated on heat and cold wave episodes. Persinger (1980)'s findings suggested significant negative correlation between winter temperature and mortality in northern American, northern Asian, and European countries. Analysing the relationship between various meteorological variables and total mortality Driscoll (1971) pointed out high temperature as the most important reason of deaths during summer. Many other studies support the relationship between temperature and deaths as well (Ellis, 1972; Ellis et al., 1975; Braga et al., 2002; Analitis et al., 2008; Deschenes and Greenstone, 2011).

Concluding this study aims to confirm the negative effects of air pollution on individuals' health, as well as, the association between the socioeconomic, household characteristics and health. The study follows the theoretical work by Grossman (1972) and Gerking and Stanley (1986) and the empirical work of Chay and Greenstone (2003). Nevertheless, this study contributes by exploring the effects of air pollution using spatially detailed disaggregated data, such as the local authority districts, and not counties or cities. In addition, this study investigates whether the weather factors, such as temperature, wind speed and precipitation are significantly related to health problems. Finally, the goal of this study is to contribute to the literature by estimating the MWTP for in-patient hospital days and visits to doctors due to air pollution, which has not been examined before in UK using the BHPS. Moreover, the majority of the studies is based mainly on cross-sectional or time-series analysis; thus exploring the effects of both air pollution, weather factors and socioeconomic characteristics and examining the MWTP for in-patient hospital days and visits to doctors into a panel data framework has not been explored in UK.

\section{Methodology}

\subsection{Theoretical framework}


One of the first simple theoretical models examining the effects of air pollution on health has been proposed by Grossman (1972), Gerking and Stanley (1986), Berger et al. (1987), Shechter (1991). Following their contributions it is assumed that the individual derives utility from consumption $(C)$ and health $(H)$ such as:

$U=U(C, H)$

The health is assumed to be a function of a vector of medical consumption goods $(M)$, air pollution (e) and exogenous individual characteristics $(X)$, such as age, education, marital status and employment status among others. Thus, the health production function can be written as:

$H=H(M, e, X)$

In a few words the individual faces the following maximization problem with respect to $C$ and $M$.

$$
\max _{C . M} U[C, H(M, e, X)]
$$

Subject to the budget constraint:

$$
N+W T=P_{C} C+P_{M} M+W T_{L}
$$

, where $N$ is the non labour income, $W$ is the labour income or wage and $T$ is the hours of market work. $P_{M}$ denotes the price of medical consumption and $P_{C}$ is the price of bundle of consumption goods $C . T_{L}$ is time lost due to illness which increases with health problems and it is:

$$
T_{L}=G(H)
$$

, where $G(H)<0$. As it is shown in Gerking and Stanley (1986), the expression for an individual's willingness to pay for an improvement in air quality associated with the private opportunity cost of time of medical consumption can be estimated and it is given by: 


$$
\frac{\partial N}{\partial e}=-\frac{H_{N}}{H_{M}} P_{M}
$$

More specifically, relation (6) is derived in 4 steps. Firstly, the utility function (3) is totally differentiated and set up to zero, which becomes:

$d U=U_{C} d_{C}+U_{H} H_{M} d M+U_{H} H_{e} d e$

Second step is to totally differentiate the budget constraint (4) and holding $d P_{i}=d W=d T=0$ for $i=C, M$.

$P_{C} d C+P_{M} d M+W G_{H} H_{M} d M-d N+W G_{H} H_{e} d e=0$

In the third step the first order conditions, from the maximization function (3) subject to the constraint (4) with respect to $C$ and $M$ are obtained and these are:

$U_{C}-\lambda U_{P_{M}}=0$

$U_{H} H_{M}-\lambda\left(P_{M}+W G_{H} H_{M}\right)=0$

Then the next step is to divide (9) by (10) and substitute into (7) and solving for dC gives:

$d C=-\left(P_{M}+W G_{H} H_{M}\right)\left(d M+\frac{H_{e}}{H_{M}} d e\right)$

Finally, substituting (11) into (8) gives relation (6). By assuming that the conditions for the implicit function theorem hold, equation (6) can be re-written as:

$\frac{\partial N}{\partial e}=-\frac{\partial M}{\partial H} \frac{\partial H}{\partial e} P_{M}$ 
, where the term $\partial M / \partial H$ measures the change in medical consumption or doctor and specialist practitioner visits or in-patient days in hospital associated with the health problems, while the term $\partial H / \partial e$ measures the direct effects of pollution to health problems.

\subsection{Binary Discrete Choice Models}

The following model of the air pollution impact on health for individual $i$, in area $j$ and at time $t$ is estimated:

$$
H_{i, j, t}=\beta_{0}+\beta_{1} e_{j, t}+\beta_{2} \log \left(y_{i, t}\right)+\beta^{\prime} z_{i, j, t}+\gamma W_{j, t}+\mu_{i}+l_{j}+\theta_{t}+l_{j} T+\varepsilon_{i, j, t}
$$

$H_{i, j, t}$ is the health problem examined. More specifically, skin conditions-allergy, chest-breathing problems and heart problems are explored. The vector $e_{j, t}$ is the measured air pollution in location $j$ and at time $t, \log \left(y_{i, t}\right)$ denotes the logarithm of household income and $z$ is a vector of individual and household characteristics, discussed in the next section. $W$ is a vector of meteorological variables, such as temperature, wind speed and precipitation. Set $\mu_{i}$ denotes the individual-fixed effects, $l_{j}$ is a location (local authority) fixed effects, $\theta_{t}$ is a time-specific vector of indicators for the day, the month the survey wave the interview took place, while $l_{j} T$ is a set of area-specific time trends. Finally, $\varepsilon_{i, j, t}$ expresses the error term which we assume to be iid.

For a marginal change of $e$, the marginal willingness-to-pay (MWTP) can be derived from differentiating (13) and setting $\mathrm{dHS}=0$. This is the income drop that would lead to the same reduction in health status than an increase in pollution. Thus, the MWTP can be computed as:

$$
M W T P=-\frac{\partial H}{\partial e} / \frac{\partial H}{\partial \log (y)}
$$

Employing panel data gives us the chance of identifying the model from changes in the pollution level within individuals rather than between individuals. Therefore, the possible endogeneity bias, which occurs due to the unobservable characteristics of the neighbourhood that may be correlated 
with pollution and health illnesses, are eliminated in a fixed effect model. Taking into account nonmovers also allow us to control for unobservable characteristics of the neighbourhood that may be correlated with pollution and health that are fixed over time. The variation in pollution level between interviews is possibly exogenous and driven by differences in the time of the year that the interviews are done, as well as variation in the level of pollution between years occurs because of the variations in economic activity and weather conditions.

Typically, three main binary choice models have been employed in literature the Linear Probability Model (LPM) and the nonlinear models Probit and Logit. The two main problems with the LPM are: nonsense predictions are possible -there is nothing to bind the value of Y to the $(0,1)$ range- and linearity does not make much sense conceptually. To address these problems we use a nonlinear binary response model. Because Probit Model does not allow us to estimate a panel regression with fixed effects we use only the Logit model. However in a number of contexts researchers have to model a dummy variable $y_{i t}$ that is function of $y_{i, t-1}$ as migration and unemployment. In our case is the health problem examined. Three methods of estimation have been suggested by Heckman (1981), Orme (1997), and Wooldridge (2005). The approach proposed by Wooldridge (2005) is followed.

\subsection{Number of Days In-patient in Hospital}

In the next model, the effects of health problem and other personal and socio-economic characteristics on the number of days being in-patient in a hospital are estimated.

$$
H d_{i, j, t}=\beta_{0}+\beta_{1} H_{i, j, t}+\beta_{2} \log \left(y_{i, t}\right)+\beta^{\prime} z_{i, j, t}+\gamma W_{j, t}+\mu_{i}+l_{j}+\theta_{t}+l_{j} T+\varepsilon_{i, j, t}
$$

, where $H d_{i, j, t}$ denotes the number of days the individual was in-patient in hospital. The remained variables are defined as in the previous models. A Fixed Effects Model is implemented in this case. 
However, having a poor health caused for example by air pollution or smoking are not the only factors leading to hospital in-patient admissions, as the number of days in-patient in hospital refer to all the cases, including i.e. car or industrial accidents. For this reason a regression model examining the number of visits to a Specialist Practitioner (SP) is described in the next section. It should be noticed that relation (12) which is the marginal willingness to pay is estimated by obtaining the marginal effects of $H$ in (15) corresponding to the term $\partial M / \partial H$, the marginal effects of $e$ from regression (13) corresponding to the term $\partial H / \partial e$ and $P_{M}$ which is the price of the medical care or in-patient hospital days.

\subsection{Visits to Specialist Practitioners (SP)}

The next model examined is the following Binary Logit Fixed Effects:

$S P_{i, j, t}=\beta_{0}+\beta_{1} H_{i, j, t}+\beta_{2} \log \left(y_{i, t}\right)+\beta^{\prime} z_{i, j, t}+\gamma W_{j, t}+\mu_{i}+l_{j}+\theta_{t}+l_{j} T+\varepsilon_{i, j, t}$

, where $S P_{i, j, t}$ denotes whether the person has visited or not a $S P$. It should be noticed that visiting a General Practitioner (GP) or a specialist is not the same. However, in the case of Great Britain individuals do not pay for National Health Services (NHS). Secondly, the $S P$ is examined because the data allow us to do; however, only visits for chest-breathing and heart problems are examined, as the visits for skin conditions are not available. Similarly with the case of the in-patient days in hospital, the relation (12) is employed where the term $\partial M / \partial H$ corresponds to the marginal effects of $H$ in (16).

Moreover, two scenarios are presented. In the first scenario $P_{M}$ is replaced by time which is necessary to visit a SP, including both transportation, waiting and consultation time. For simplicity, 3 hours are examined. In the second scenario two prices are used. The first is a monthly fee of $£ 10$ for using National Health Service (NHS) and $£ 20$ for a night stay in hospital. However, the latter is used for the number of in-patient days in hospital instead of visiting a SP. This scenario is examined based on the proposal by Lord Warner a former Labour health minister (Borland 2014). 


\section{Data used}

We use the British Household Panel Survey (BHPS) that is an annual survey of each adult member of a nationally representative sample of more than 5,000 households which started in 1991 and has being carried out by the Economic and Social Research Council (ESRC) United Kingdom (UK) Longitudinal Studies Centre with the Institute for Social and Economic Research at the University of Essex. More specifically, the wave 1 panel contains 5,500 households and 10,300 individuals coming from 250 areas of Great Britain. In 1999 and 2001, 1,500 and 2,000 households respectively from Scotland and Northern Ireland were included, making BHPS a unique dataset for UK research.

Additional samples of 1,500 households in each of Scotland and Wales were added to the main sample in 1999, and in 2001 a sample of 2,000 households was added in Northern Ireland, making the panel suitable for UK-wide research. Individuals moving out or into the original household are also followed (Taylor et al. 2010). The main aim of the survey is to realize the social and economic changes and development at the individual and household level in UK. Topics of possible research include labour market behaviour, health, education and training, household formation and housing, dissolution and fertility, happiness, life satisfaction, social and political attitudes and values. The data period used in this study covers the waves between 1 and 18 and years between 1991 and 2009 .

One of the most important and unique characteristics of BHPS is its panel structure which allow us to follow the individuals and the inclusion of their history into a fixed effects model.

On the other hand, one of the main limitations of BHPS is the fact that it suffers from the typical panel data problems like attrition and non-response. Another important drawback is that full life history records of individuals are only complete for BHPS respondents who were interviewed at waves 1-2. Therefore, for the new adult entrants to the BHPS, such as those incorporated by the extension samples- from Scotland and Wales at wave 9 (1999) and Northern Ireland at wave 11 (2001)- the full life history information is unavailable for them. 
The BHPS has been extensively used for empirical work on life satisfaction / happiness (Clark and Oswald 1994; Giovanis 2014). Based on the literature the individual and household variables of interest are household income ${ }^{\mathrm{ii}}$, gender, age, family size or household size, job status, house tenure, marital status, education level and local authority districts. Additionally, the regressions control for the day of the week, month of the year and the wave of the survey, and an area-specific trend since these variables are likely to be correlated both with health status and pollution level. In addition, weather variables are included into the regression analysis and these are: the average, minimum and maximum temperature, wind speed and precipitation. Since weather can also have a direct impact on one's health (Deschenes and Greenstone, 2011), it is also an important variable to control in the regression. In all regressions the same control variables are included. Three different binary variables are examined. The first is whether the respondent has skin conditions and allergy problems. The second is related to chest-breathing problems while the third one is about heart problems.

Furthermore, in order to reduce the variation, to increase the robustness of the estimations and in an effort to capture the missing values of air pollutants, the monthly average preceding the interview is computed. The average monthly values are more appropriate especially because the effects of air pollution on health problems examined cannot be always instantaneous, with the exception of special groups of people, as children suffering from asthma or old people suffering from heart and cardiovascular diseases. However, the days prior to interview as well as the weekly averages preceding the interview are considered. The former is taken into consideration because the time of the interview is unknown, therefore the air pollution on the same day may have little or insignificant effect on health problems, especially when the interview is conducted during the early morning hours. In addition, the household income of the last month is considered.

Two major air pollutants are examined: Ground-level ozone $\left(\mathrm{O}_{3}\right)$ and Carbon Monoxide $(\mathrm{CO})$. The air pollutants are based on daily frequency and measured in $\mu \mathrm{g} / \mathrm{m}^{3}$. In order to match the air pollution emissions with the individuals the following steps are applied. Firstly, the exact location of 
the air monitoring stations is known given in grid points - easting and northing- which can be found on DEFRA website. Secondly, we have special access on individuals' local authority district (LAD).

In order to convert the point data from the monitoring stations into regional data up LAD Level we use the inverse distance weighting (IDW); a GIS-based interpolation method. In IDW, the weight of a sampled data point is inversely proportional to its distance from the estimated value. The final level of regional aggregation in the analysis is based on local authority district level. More specifically, firstly the centroid of each local authority district is calculated. Then the distance between the air pollution monitor and the centre of the local authority district is measured using the Haversine formula ${ }^{\mathrm{iii}}$. Then the pollution in LAD level is calculated as:

$$
F(x, y)=\sum_{i=1}^{n} w_{i} f_{i}
$$

, where $n$ is the number of scatter points in the set, $f_{i}$ are the prescribed function values at the scatter points, which in our case refer to the centroids of the local authority districts, and $w_{i}$ are the weight functions assigned to each scatter point. The classical form of the weight function is:

$$
w_{i}=\frac{d_{i}^{-p}}{\sum_{j-1}^{n} d_{j}^{-p}}
$$

$p$ is an arbitrary positive real number called the power parameter, typically $p=2$ is used. Nevertheless, $p=3$ is used similar to the study by Luechinger (2009), to map the cubic grids and $d_{i}$ is the distance from the scatter point (centroids of the local authority districts) to the interpolation point (coordinates of the air monitoring stations) calculated using the Haversine formula (see endnote iii for the precise formula). However for presentation convenience the simple Euclidean distance is: 
$d_{i}=\sqrt{\left(x-x_{i}\right)^{2}-\left(y-y_{i}\right)^{2}}$

, where $(x, y)$ are the coordinates of the interpolation point and $\left(x_{i}, y_{i}\right)$ are the coordinates of each scatter point. The weighting function always ranges between 0 and 1 . It takes value 1 at the scatter point, while the value becomes 0 with increases of the distance from this point. The normalization process is applied to weighting functions so they sum up to unity (Franke and Nielson, 1980). Various researches used as distance threshold 20 kilometres. However, a major issue in measuring pollution in this way is that the choice of 20 kilometres as the cutoff may be arbitrary. ${ }^{\text {iv }}$

The unique feature of these restricted Census data is that they provide information about the location of individual people's residence down to a disaggregated level which allows us to identify far more accurately than using other geographical references, such as cities, counties or countries. Regarding regression (13) the dependent variable is a dummy taking value 1 whether the individual suffers from a specific health problem or not. In regression (15) the dependent variable is the number of the hospital in-patient days; thus a fixed effects model is applied, while in regression (16) the dependent variable is a dummy obtaining value 1 if the individual has visited a SP practitioner for chest or heart problems and 0 otherwise.

In table 1 the summary statistics are presented. More specifically, in panel A the continuous variables, household income, air pollutants, weather data and the number of hospital in-patient days in the last year are reported, while in panel B the discrete variables of whether the individuals suffer from health problems and whether they have visited a SP practitioner are presented. The average number of hospital in-patient days is 9.7, while the minimum and maximum number is 0 and 365 days respectively. Regarding the health problems, the 12.45 per cent of the sample states that it suffers from skin conditions and allergy, the 14.21 suffers from chest and breathing problems, while the 17.04 per cent suffers from heart problems. The 14.32 per cent of the sample has stated that has visited SP practitioner for chest checkup and the 46.50 has visited SP for heart problems checkup.

Table 2 presents the correlation matrix between the various pollutants and health illnesses. These correlations are based on the average pollution levels at the nearest monitoring station at the day 
before the interview. The correlation between carbon monoxide and ground-level ozone is negative induced by seasonal variations in the occurrence of these pollutants, where $\mathrm{O}_{3}$ is higher during the spring and summer terms, while higher concentration levels for $\mathrm{CO}$ are reported mainly during the winter. Cristofanelli et al. (2013) examined variability of ozone, carbon monoxide and equivalent black carbon at the Italian Climate Observatory "O. Vittori” (ICOOV), part of the Mt. Cimone global GAW-WMO station in Italy. Cristofanelli et al. (2013) found that the $\mathrm{O}_{3}$ and $\mathrm{CO}$ are negatively correlated during the period October-December (Cristofanelli et al. 2013), while Parrish et al. (1998) found a negative correlation during the winter. This indicates that there is a reduced photochemical production, where positive $\mathrm{O}_{3}$ mostly coincides with negative $\mathrm{CO}$ indicating that clean air-masses, possibly from the free troposphere or the lower stratosphere (Parrish, et al. 1998; Cristofanelli et al. 2013) could lead to increase of $\mathrm{O}_{3}$.

\section{(Insert tables 1-2)}

\section{Empirical Results}

\subsection{Air Pollution and Health Status}

Equation (13) is estimated separately for each pollutant in order to disentangle their effects. In table 3, the estimates of binary Logit model with fixed effects for skin conditions and allergy health problems are reported. The air pollutants and income present the expected positive and negative signs respectively. Therefore a rise in air pollution increases the probability of health deterioration occurrence. The results for the total, non-movers and movers within $\mathrm{UK}$ for $\mathrm{CO}$ are reported in columns (1), (2) and (3) respectively. Similarly, the estimates for $\mathrm{O}_{3}$ are presented in columns (4)(6). It should be noticed that the sum of non-movers and movers within Britain is not equal to the total sample. The reason is that additional classes of moving status are included, as moving from abroad or unknown status, which classes are not useful for the analysis, because the main interest of the analysis is the respondents who move across Britain. 
Age is statistically insignificant indicating that allergy and skin condition problems are not related with age. Regarding household size its impact on health status is positive. The literature provides evidence that family support and size has a useful and protective effect on people with a chronic disease (Aldwin and Greenberger 1987; Doornbos 2001). Therefore, household size and support can be a proxy for the health care at home indicating that this type of health care may replace the medical care obtained in hospitals and clinics and improves people's health living in households with big size than people who do not.

The effects of weather and meteorological factors are insignificant, with the exception of maximum temperature and precipitation. Precipitation has negative impact on skin conditions which might come from the fact that rainfall and acid rain include chemical compounds and air pollutants, such as $\mathrm{CO}$. Thus, high frequencies of acid rain may have a negative effect on the health condition of human. Similarly, the effects of maximum temperature on health status are negative and significant, as higher temperature is associated with higher air pollution concentration levels. Regarding the socio-economic status (SES) all the factors are insignificant, as job status, marital status, education level and house tenure. The only exception is the individuals who rent the house regarding total and non-movers sample. On the other hand marital status is important determinant of skin conditions and allergy regarding the movers sample. More specifically, the individuals who live together as a couple, as well as, widowed and divorced individuals report a higher probability of suffering by skin conditions and allergy problems than married individuals. Finally, there is no difference between being smoker and non-smoker on the probability of suffering from skin conditions and allergy health problems.

The next step is to compute the marginal willingness-to-pay (MWTP). This is the level of household income that makes individuals indifferent to a drop of a unit in a pollutant. Relation (14) is employed, where the term $\partial H / \partial e$ is the marginal effect of $e$ in regression (13), while the term $\partial H / \log (y)$ is the marginal effect of the logarithm of household income $\log (y)$. 
Finally, in order to compute the average MWTP, the average household income is multiplied with the MWTP value. Since household income is measured in monthly basis, the MWTP values are multiplied by 12 in order to get the yearly values. The average (MWTP) for a reduction in CO of a one unit is $£ 84, £ 87$ and $£ 70$ per year for total, non-movers and movers sample respectively as it is shown in table 3 . The respective figures are $£ 52, £ 65$ and $£ 45$ for $\mathrm{O}_{3}$. However, the MWTP for the movers sample of both air pollutants is insignificant. It should be noticed that the MWTP are expressed in percentage; thus for example in table 3 and column (1) the MWTP is 0.00285 and multiplying by the average household income and 12 months the annual monetary MWTP becomes $£ 84$.

\section{(Insert table 3)}

In tables 4 and 5 the estimates for chest-breathing and heart problems respectively are reported. In that case the air pollutants and income present the same coefficients as in table 3. However, there are differences. Firstly, the air pollutants coefficients become higher indicating that air pollution has stronger negative effects on people who suffer from chest-breathing and heart problems. Secondly, the age coefficient now becomes significant, indicating that age is a significant factor for individuals who report the above-mentioned health problems. This implies that people generally encounter deterioration in health with old age; however this does not imply that the decline in health with age is experienced at the same rate by individuals. Moreover, not all the people are willing to pay the same amount for an improvement on health status.

A strong positive relationship between socio-economic status (SES) and health status has been found in previous researches. SES is important to health not only for those in poverty, but for whom have different levels of income. On average, individuals who are more advantaged economically have better health levels. Especially the well-educated and higher income classes have lower rates of morbidity, mortality and better rates of health status. On the contrary to the results of table 3 , the findings in tables 4 -5 suggest a strong relationship between socio-economic status (SES). The results are consistent with other studies (Benzeval et al. 2000; Prus 2001; Beckett and Elliott 2002). In 
addition, smoking is an important determinant as the non-smokers are less likely to suffer from chestbreathing and heart health problems than those who are smokers.

\section{(Insert tables 4-5)}

Based on table 4, the average marginal willingness-to-pay (MWTP) for a reduction in CO of a one unit is $£ 185, £ 218$ and $£ 84$ per year for total, non-movers and movers sample respectively, while the respective values for $\mathrm{O}_{3}$ are $£ 173, £ 208$ and $£ 60$. Similarly, for the heart problems and based on the findings of table 5 the MWTP for CO is $£ 189, £ 222$ and $£ 132$ for total, non-movers and movers sample respectively, while the respective figures for $\mathrm{O}_{3}$ are $£ 178, £ 216$ and $£ 134$. In the cases of chest-breathing and heart health problems and regarding movers sample the air pollutants are significant factors, while they are not in the case of skin conditions and allergy problems as it has been shown in table 3 .

In table 6 the results from the dynamic binary Probit random effects model and the non-movers sample are reported. Only the coefficient of the lagged health problem, household income and air pollutants are reported as the results for the rest of the variables are similar with those found in tables 3-5. The results of table 6 are useful to explore the adaptation level, when the air pollution is taken into consideration. The parameter of the dependent variable with one lag indicates the extent to which an individual changes his or her adaptation level and adapts to living conditions represented by the stimulus level in the preceding period and it is assumed that it ranges between 0 and 1 . If it is equal to 1 , the adaptation level is completely determined by the level of the other factors in the previous period, while if it is 0 , the level of the other explanatory variables do not influence the current adaptation level or adaptation does not take place. Thus, both the recent changes and the long-term development of living conditions would determine a person's health situation. Regarding the skin conditions and allergy problems the MWTP for a unit drop in $\mathrm{CO}$ and $\mathrm{O}_{3}$ is respectively $£ 76$ and $£ 60$, while the respective figures for chest-breathing problems are $£ 215$ and $£ 203$ for $\mathrm{CO}$ and $\mathrm{O}_{3}$ 
respectively. Finally, the average MWTP for $\mathrm{CO}$ and $\mathrm{O}_{3}$ is respectively $£ 218$ and $£ 208$ in the case of heart health problems.

(Insert table 6)

\subsection{Air Pollution, Health Problems, In-patient Hospital Days and Visits to SP}

In table 7 the results of Fixed Effects Model (7) are reported. More specifically, regarding the first column the regression for the number of days in-patient in hospital and concerning the chest breathing problems are reported, Similarly, in the second column the results for the heart problems are presented. The respective regressions for visits to SP are presented in the third and fourth column. The sign of the coefficients is similar with those presented in the previous tables. More specifically, a higher household income leads to a reduction of the in-patient days in NHS hospital. Individuals with poor health status stay on average 2 days more in hospital than individuals with good health status.

In columns (3)-(4) of table (7) the results of Fixed Effects Logit Regression (16) for whether the individual has visited a SP practitioner or not are reported. In table 8 the monetary value of the average MWTP for number of in-patient days in hospital and visits in SP are presented. In this case, relation (12) is used in order to estimate the average MWTP. More precisely, the term $\partial M / \partial H$ is the marginal effect of $H$ in regression (15) -number of hospital in-patient days- with respect to health status. The same is defined for the visits to SP practitioner and regression (16), where $M$ denotes the mitigating behaviour, such as visits to doctors etc. The term $\partial H / \partial e$ of relation (12) is the partial derivative or marginal effect of the health function with respect to air pollution derived by the tables 4-5 for chests and heart problems respectively. In this point it should be noticed that in the fixed effects regression (15) the marginal effects are equal to the coefficients, while this does not hold for the regressions (13) and (16), since Logit fixed effects and dynamic Probit models are nonlinear. 
Next the relation (12) based on the results of tables 3-5 and 7 is used. Based on NHS (2010) the national average cost of an elective (planned) in-patient stay excluding excess bed days is $£ 2,749$, while the cost for non-elective (unplanned) is $£ 527$ for short stays and $£ 2,197$ for long stays. In the case examined only 1 in-patient day is taken into consideration as it is unknown from the data how many consecutively days the individual was in-patient. In the case of table 8 and panel A the possible fee of $£ 20$ per stay proposed by Lord Warner a former Labour health minister Borland (2014) is implemented.

Using the information provided by UK Government the minimum wage in 2010 was 5.5 (https://www.gov.uk/national-minimum-wage-rates). This is a very simplified example and the minimum wage is used as the opportunity cost for being in hospital instead of working. Moreover the fee of $£ 20$ is equivalent with almost 2.5 working hours paid in minimum hourly wage plus the three hours scenario which might be necessary for transportation, waiting and consultation time.

Based on the table 7 and the fixed effects regression for the number of in-patient days, the term $\partial M / \partial H$ is 1.515 , while based on table 4 , column (2), since we are interested for the non-movers and for CO the coefficient is 0.0607 . Thus, using as a scenario 5.5 hours ( 3 hours for transportation, waiting and consultation time plus the 2.5 working hours lost which are equivalent to the $£ 20$, considering the minimum wage) the MWTP will be $0.00061 * 1.515 * 5.5=0.0050$ and multiplying by the average household income and 12 months, the annual monetary MWTP value is $£ 155$. As is has been mentioned before, the 1.515 refers to the marginal effect of $H$ in regression (15), which is equivalent to the coefficient, since it is a linear regression. On the other hand, 0.00061 is the marginal effect of $e(0.0607)$ in table 4.

Thus the cost for one unit of CO per year and individuals with poor health status is $£ 155$ and $£ 209$ for chest-breathing and heart problems respectively, while the MWTP values for $\mathrm{O}_{3}$ are $£ 147$ and $£ 180$. However, the fee of $£ 20$ per stay in hospital is not implemented and the cost for individual is free, but there is actually a cost for taxpayers. Even if $P_{M}$ is zero then the MWTP becomes $£ 30$ and 
$£ 26$ for $\mathrm{CO}$ and $\mathrm{O}_{3}$ respectively for a one unit decrease in air pollutants in the case of chest-breathing problems. Similarly, regarding heart problems the MWTP is $£ 37$ and $£ 33$ for $\mathrm{CO}$ and $\mathrm{O}_{3}$ respectively.

\section{(Insert tables 7-8)}

Based the results of tables 7-8 and considering the first scenario, a reduction of roughly 18 units in air pollutants examined, for chest-breathing and heart problems will be equal at the elective inpatient stay costs of $£ 2,749(£ 2,749 / £ 150=18)$, since the MWTP for one unit increase is $£ 150$. For a non-elective long stay $(£ 2,197)$ a reduction of roughly 14 units in air pollutants is needed. Concerning a non-elective short stay (£527) a 3-4 unit reduction covers this cost.

Therefore, examining the determinants of health problems and especially the air pollution can be a very useful tool for policy makers on health care system. As the majority of the studies examine the effects of SES on health status and the age as the most important factors, air pollution effects on health status and health care system costs are neglected.

In panel B the MWTP for visits in SP and for taking 3 hours for $P_{M}$ are presented. For chestbreathing problems the MWTP is equal at $£ 90$ and $£ 86$ for $\mathrm{CO}$ and $\mathrm{O}_{3}$ respectively, while for heart problems is $£ 131$ and $£ 116$ respectively for $\mathrm{CO}$ and $\mathrm{O}_{3}$. Similarly, in panel $\mathrm{C}$ the MWTP monetary values, considering the possible scenario of a $£ 10$ monthly fee implementation, which is equivalent with 1.8 hours in terms of minimum hourly wage taken as opportunity cost plus the three hours scenario are reported. In that case the MWTP for chest-breathing problems is equal at $£ 150$ and $£ 142$ for $\mathrm{CO}$ and $\mathrm{O}_{3}$ respectively, while the respective values for heart problems are $£ 182$ and $£ 157$.

Léger (2001) examined the relationship between $\mathrm{O}_{3}$ and health status in Montreal of Canada during the period 1992-1993 found that for a 50 per cent reduction of ozone the MWTP is $\$ 1.50$ per year, while when physical limitations and time off are included, this average willingness to pay for a 50 per cent reduction of ozone is almost $\$ 29.00$ annually. The results are different for various reasons. Firstly, the findings have been inflated in 2009 the last year of the BHPS in order to have comparable estimates with the present values. Secondly, BHPS is a long panel capturing 18 years in UK, instead 
of only one city as Montreal. Thirdly, the sample includes people from various socio-economic status and income. Lastly, this study explores also the in-patient days in hospital as well as it accounts for the proposed fees for using GP and hospital stays.

\section{Conclusions}

This study has used a set of panel micro-data on self-reported health status from the British Household Survey. Overall, the results are consistent with the previous studies which found a significant and negative impact of air pollution on health status (Gerking and Stanley, 1986; Dockery et al., 1993; Chay and Greenstone, 2003; Currie and Neidell, 2005). In addition, the results confirm that socioeconomic and household characteristics are significant determinants of individual's health status, as the previous studies found. More specifically, the results are consistent with previous studies, where married, employed and educated individuals are more likely to present better health (Benzeval et al. 2000; Adams et al. 2003; Contoyannis et al. 2004), while household size can be also an important factor of health (Aldwin and Greenberger 1987; Doornbos 2001).

The results showed that the MWTP for a one unit drop in CO per year ranges between $£ 122-£ 141$, while the MWTP for $\mathrm{O}_{3}$ ranges between $£ 128-£ 149$. It is suggested that various cases can be examined, such as separate estimates for female and male, age groups, urban and rural areas, different periods and others. Moreover higher frequency air pollution data can be examined, as weekly or daily in order to examine the mitigating behaviour.

This approach has been used to assess how willingness to pay varies over time and by region, age, income, education and level of pollution among others. Additionally, one important point of this approach is that the estimated coefficients can be used to calculate the marginal rate of substitution between income and air quality directly, and thus it is not afflicted by the contingent valuation problem of differences between stated willingness to pay and willingness to accept. Moreover, this approach can be very helpful in environmental and economic policy and decision making. Generally, the results show that this approach contains very useful information on individuals' preferences and 
at the same time expands the economic tools in the area of non-market evaluation and it can be used as a supplementary method to traditional stated and revealed preferences methods.

Lastly, the results show that the MWTP an in-patient day in hospital for a one unit reduction in pollution range between $£ 26-£ 30$, where is ranged between $£ 150-£ 200$ in the case where the fee of $£ 20$ per stay will be implemented. In other words, for every unit increase in air pollution the in-patient hospital costs increase the costs for the individuals either directly by paying an additional fee or indirectly by paying taxes. Considering that the in-patient elective-planned stay cost per day is $£ 2,749$, a 4-5 unit decrease in air pollutants will lead to a MWTP equivalent to the in-patient cost. Differently putting a five unit increase on the air pollution increases the costs by the amount of in-patient electiveplanned stay cost, while a four unit increase leads to an equivalent increase of the in-patient nonelective unplanned long stay cost per day.

\section{Acknowledgements}

This research has been funded by the Scientific and Technological Research Council of Turkey (TUBITAK) Scientist Support Directorate (BIDEB) under the Postdoctoral Research Grants Funding Scheme 2219.

This work has been based on data from the British Household Panel Survey, Waves 1-18, 1991-2009: Conditional Access, Local Authority Districts, produced by the Institute for Social and Economic Research (ISER) at the University of Essex, sponsored by the Economic and Social Research Council (ESRC), and supplied by the UK Data Archive. The data are the copyright of ISER. The use of the data in this work does not imply the endorsement of ISER, ESRC or the UK Data Archive in relation to the interpretation or analysis of the data. 


\section{References}

Adams, P., Hurd, D.M., McFadden, L.D., Merrill, A. and Ribeiro, T. (2003). 'Healthy, wealthy and wise? Tests for direct causal paths between health and socioeconomic status', Journal of Econometrics, Vol. 112, No. 1, pp. 3-56.

Aldwin, C. and Greenberger, E. (1987). 'Cultural differences in the predictors of depression', American Journal of Community Psychology, Vol. 15, No. 6, 789-813.

Analitis, A., Katsouyanni, K., Biggeri, A., Baccini, M., Forsberg, B., Bisanti, L., Kirchmayer, U., Ballester, F., Cadum, E., Goodman, P.G., Hojs, A., Sunyer, J., Tiittanen, P. and Michelozzi, P. (2008). Effects of Cold Weather on Mortality: Results From 15 European Cities Within the PHEWE Project', American Journal of Epidemiology, Vol. 168, No. 12, pp. 1397-1408.

Beckett, M. and Elliott, M. N. (2002). 'Does the Association Between Marital Status and Health Vary by Sex, Race and Ethnicity? Rand, Labor and Population Program', Working Paper Series 0208 .

Benzeval, M., Taylor, J. and Judge, K. (2000). 'Evidence on the relationship between low income and poor health: Is the Government doing enough?' Fiscal Studies, Vol. 21, No. 3, pp. 375399.

Berger, M.C., Blomqvist, G.C., Kenkel, D. and Tolley, G.S. (1987) 'Valuing changes in health risks: a comparison of alternative measures', Southern Economic Journal, Vol. 53, No. 4, pp. 967984.

Borland, S., (2014). Call for $£ 10$ a month fee to use NHS and $£ 20$ a night to stay in hospital: Former Labour health minister says out-of-date service needs to the cash. Daily Mail. http://www.dailymail.co.uk/news/article-2592986. [Accessed 13 May 2014].

Braga, A.L.F., Zanobetti, A. and Schwartz, J. (2002). 'The effect of weather on respiratory and cardiovascular deaths in 12 U.S. cities', Environmental Health Perspectives, Vol. 110, No. 9, pp. 859-863.

Chay, K. and Greenstone, M. (2003). 'Air Quality, Infant Mortality, and the Clean Air Act of 1970', NBER Working Paper No. 10053. Cambridge, MA.

Clark, E.A. and Oswald, J.A. (1994). 'Unhappiness and Unemployment', The Economic Journal, Vol. 104, No. 424, pp. 648-659.

Contoyannis, P., Jones, M.A. and Rice, N. (2004). 'The dynamics of health in the British Household Panel Survey', Journal of Applied Econometrics, Vol. 19, No. 4, pp. 473-503.

Contoyannis, P. and Jones, M.A. (2004). 'Socioeconomic status, health and lifestyle', Journal of Health Economics, Vol. 23, No. 5, pp. 965-995.

Cristofanelli, P., Fierli, F., Marinoni, A., Calzolari, F., Duchi, R., Burkhart, J., Stohl, A., Maione, M., Arduini, J. and Bonasoni, P. (2013). 'Influence of biomass burning and anthropogenic emissions on ozone, carbon monoxide and black carbon at the Mt. Cimone GAW-WMO global station (Italy, $2165 \mathrm{~m}$ a.s.1.)', Atmospheric Chemistry and Physics, Vol. 13, No. 1, pp. 15-30.

Currie, J. and Neidell, M. (2005). 'Air Pollution and Infant Health: What Can We Learn from California's Recent Experience?' The Quarterly Journal of Economics, Vol. 120, No. 3, pp. 1003-1030.

DEFRA, (2010). Air Pollution: Action in a changing climate. Department for Environment. Food and Rural Affairs. London, England.

Delfino, R.J., Murphy-Moulton A.M. and Becklake, M.R. (1998). 'Emergency room visits for respiratory illnesses among the elderly in Montreal: association with low level ozone exposure', Environmental Research, Section A, Vol. 76, No. 2, pp. 67 - 77.

Deschenes, O. and Greenstone, M. (2011). Climate Change, Mortality, and Adaptation: Evidence from Annual Fluctuations in Weather in the US. American Economic Journal: Applied Economics, Vol. 3, No. 4, pp. 152-185.

Dockery, D., Pope, C. A., Xiping, X., Spengler, J., Ware, J., Fay, M., Ferris, B. and Speizer, F. (1993). 'An Association between Air Pollution and Mortality in Six U.S. Cities', New England Journal of Medicine, Vol. 329, No. 24, pp. 1753-1759. 
Doornbos, M.M. (2001). 'Professional support for family care-givers of people with serious and persistent mental illnesses', Journal of Psychosocial Nursing Mental Health Service, Vol. 39, No. 12, pp. 38-45.

Driscoll, D.M. (1971) 'Base lines for measuring adverse effects of air pollution: Some evidence for weather effects on mortality', Environmental Research, Vol. 4, No. 3, pp. 233-242.

Ellis, F.P. (1972). 'Mortality from heat illness and heat-aggravated illness in the United States', Environmental Research, Vol. 5, No. 1, pp. 504-512.

Ellis, F.P., F. Nelson, and L. Pincus, 1975: Mortality during heat wave in New York City, July 1972 and August and September 1973. Environmental Research, Vol. 10, No. 1, pp. 1-13

Ferreira, S., Akay, A., Brereton, F., Cuñado, J., Martinsson, P., Moro, M. and Ningal, T.F. (2013). 'Life Satisfaction and Air Quality in Europe', Stirling Economics Discussion Paper 2013-02.

Franke, R. and Nielson, G. (1980). 'Smooth Interpolation of Large Sets of Scattered Data', International Journal for Numerical Methods in Engineering, Vol. 15, No. 11, pp. 1691-1704.

Frey, B., Luechinger, S. and Stutzer, A. (2010). 'The life satisfaction approach to environmental valuation', Annual Review of Resource Economics, Vol. 2, pp. 139-160.

Gerking, S. and Stanley, R.L. (1986). An Economic Analysis of Air Pollution and Health: The Case of St. Louis. The Review of Economics and Statistics, Vol. 68, No. 1, pp. 115-121.

Giovanis, E. (2014). 'Relationship between well-being and recycling rates: evidence from life satisfaction approach in Britain', Journal of Environmental Economics and Policy, Vol. 3, No. 2, pp. 201-214.

Grossman, M. (1972). 'On the concept of health capital and the demand for health', Journal of Political Economy Vol. 80, No. 2, pp. 223-255

Heckman, J. J. (1981). The incidental parameters problem and the problem of initial conditions in estimating a discrete time-discrete data stochastic process. In Structural Analysis of Discrete Data and Econometric Applications Manski, C. F. and. McFadden, D. L. (eds), pp. 114-178. Cambridge, MA: MIT Press.

Léger, P. T. (2001). 'Willingness to Pay for Improvements in Air Quality', Cahiers de recherche 0102, HEC Montréal, Institut d'économie appliquée.

Luechinger, S. (2009). 'Valuing Air Quality Using the Life Satisfaction Approach', The Economic Journal, Vol. 119, No. 536, pp. 482-515.

Luechinger, S. (2010). 'Life Satisfaction and Transboundary Air Pollution', Economics Letters, Vol. 107, No. 1, pp. 4-6.

McConnell, R., Berhane, K., Yao, L., Jerrett M, Lurmann, F., Gilliland, F., Künzli, N., Gauderman, J., Avol, E., Thomas, D. and Peters, J. (2006). 'Traffic, Susceptibility, and Childhood Asthma', Archives of Environmental Health, Vol. 114, No. 5, pp. 766-772.

O'Neill, M.S., Loomis, D. and Borja-Aburto, V.H. (2004). 'Ozone, area social conditions and mortality in Mexico City', Environmental Research, Vol. 94, No. 3, pp. 234-242.

Oosterlee, A., Drijver, M., Lebret, E. and Brunekreef, B. (1996). 'Chronic respiratory symptoms in children and adults living along streets with high traffic density', Occupation and Environmental Medicine, Vol. 53, No. 4, pp. 241-247

Orme, C.D. (1997). 'The Initial Conditions Problem and Two-Step Estimation in Discrete Panel Data Models', Discussion Paper No. 9633, School of Social Sciences, University of Manchester, United Kingdom.

Ostro, B., Broadwin, R., Green, S., Feng, W.Y. and Lipsett, M. (2006). 'Fine Particulate Air Pollution and Mortality in Nine California Counties: Results from CALFINE', Environmental Health Perspectives, Vol. 114, No. 1, pp. 29-33.

Parrish, D.D., Trainer, M., Holloway, J.S., Yee, J.E., Warshawsky, M.S., Fehsenfeld, F.C., Forbes, G.L. and Moody, J.L. (1998). 'Relationships between ozone and carbon monoxide at surface sites in the North Atlantic region', Journal of Geophysical Research, Vol. 103, No. D11, 13,357-13,376.

Persinger, M.A. (1980). The Weather Matrix and Human Behaviour, New York: Praeger Publishers Inc. 
Prus, G.S. (2001). 'The Relationship between Age, Socio-Economic Status and Health among Adult Canadians. Social and Economics Dimensions of An Ageing Population', SEDAP Research Paper No. 57.

Shechter, M. (1991) 'A comparative study of environmental amenity valuations', Environmental and Resource Economics, Vol. 1, No. 2, pp. 129-155.

Shima, M., Nitta, Y. and Adachi, M. (2003). 'Traffic-related air pollution and respiratory symptoms in children living along trunk roads in Chiba Prefecture, Japan', Journal of Epidemiology, Vol. 13, No. 2, pp. 108-119.

Taylor, M.C., Brice, J., Buck, N. and Lane, E.L. (2010). British Household Panel Survey User Manual Volume A: Introduction, technical report and appendices. Colchester: University of Essex.

Van Vliet, P., Knape, M., De Hartog, J., Janssen, N., Hassema, H. and Brunekreef, B. (1997). 'Motor vehicle exhaust and chronic respiratory symptoms in children living near freeways', Environmental Research, Vol. 74, No. 2, pp. 122-132.

Wilhelm, M. and Ritz, B. (2003). 'Residential proximity to traffic and adverse birth outcomes in Los Angeles County, California, 1994 - 1996', Environmental Health Perspectives, Vol. 111, No. 2, pp. $207-216$.

Wooldridge, J. (2005). 'Simple solutions to the initial conditions problem in dynamic, nonlinear panel data models with unobserved heterogeneity', Journal of Applied Econometrics, Vol. 20, No. 1, pp. 39-54. 
Table 1. Summary statistics of income and air pollutants

\begin{tabular}{ccccc}
\hline Variables & Mean & $\begin{array}{c}\text { Standard } \\
\text { Deviation }\end{array}$ & Minimum & Maximum \\
\hline & Panel A: Continuous variables & \\
\hline Household income & $2,454.937$ & $1,966.581$ & 0.0 & $86,703.29$ \\
Ozone $\left(\mathrm{O}_{3}\right)$ & 9.7348 & 20.1842 & 0.0 & 365 \\
Number of hospital in-patient days & 35.273 & 17.351 & 0.0 & 124 \\
Carbon Monoxide $(\mathrm{CO})$ & 0.4309 & 0.3828 & 0.0 & 10.7 \\
Average temperature & 50.417 & 7.356 & 13 & 35.4 \\
Wind speed & 8.374 & 15.438 & 0.0 & 6.800 \\
Precipitation & 3.581 & 2.042 & 0.69 & 80.60 \\
Minimum Temperature & 44.593 & 4.022 & 19 & 30.90 \\
Maximum Temperature & 55.725 & 3.947 & & \\
\hline & Panel B: Discrete variables & & \\
\hline Skin Conditions & Yes & No & & \\
Chest and Breathing & 12.45 & 87.55 & 85.79 & \\
Heart and Blood Pressure & 14.21 & 82.96 & & \\
Visits to SP practitioner chest problems & 17.04 & 85.68 & &
\end{tabular}

Table 2. Correlation between air pollutants and health problems

\begin{tabular}{ccccc}
\hline & $\begin{array}{c}\text { Carbon } \\
\text { Monoxide }\end{array}$ & $\begin{array}{c}\text { Skin } \\
\text { Conditions }\end{array}$ & $\begin{array}{c}\text { Chest and } \\
\text { Breathing }\end{array}$ & $\begin{array}{c}\text { Heart and } \\
\text { Blood } \\
\text { Pressure }\end{array}$ \\
\hline $\begin{array}{c}\text { Ground- } \\
\text { Level Ozone }\end{array}$ & $\begin{array}{c}-0.3457 \\
(0.000)^{* * *}\end{array}$ & $\begin{array}{c}0.0163 \\
(0.000)^{* * *}\end{array}$ & $\begin{array}{c}0.0129 \\
(0.000)^{* * *}\end{array}$ & $\begin{array}{c}0.0151 \\
(0.000) * * *\end{array}$ \\
$\begin{array}{c}\text { Carbon } \\
\text { Monoxide }\end{array}$ & & 0.0204 & 0.0149 & 0.0114 \\
\hline
\end{tabular}

$\mathrm{p}$-values are reported between brackets, ${ }^{* * *}$ indicates significance at $1 \%$ level. 
Table 3. Binary Logistic Regressions Fixed Effects for Skin Conditions and Allergy Health Problems

\begin{tabular}{|c|c|c|c|c|c|c|}
\hline Model & (1) & (2) & (3) & (4) & (5) & (6) \\
\hline & \multicolumn{3}{|c|}{$\mathrm{CO}$} & \multicolumn{3}{|c|}{$\mathrm{O}_{3}$} \\
\hline \multirow[t]{2}{*}{ Household Income } & -0.0282 & -0.0355 & -0.0548 & -0.0270 & -0.0326 & -0.0574 \\
\hline & $(0.0131)^{* *}$ & $(0.0176)^{* *}$ & $(0.0313)^{*}$ & $(0.0132)^{* *}$ & $(0.0154)^{* *}$ & $(0.0341)^{*}$ \\
\hline \multirow[t]{2}{*}{ Air Pollutant } & 0.0213 & 0.0285 & 0.0165 & 0.0166 & 0.0213 & 0.0153 \\
\hline & $(0.0102)^{* *}$ & $(0.0135)^{* *}$ & $(0.0217)$ & $(0.0078)^{* *}$ & $(0.0102)^{* *}$ & $(0.0171)$ \\
\hline \multirow[t]{2}{*}{ Age } & 0.0113 & 0.0175 & 0.0169 & 0.0128 & 0.0372 & 0.0124 \\
\hline & $(0.0072)$ & $(0.0145)$ & $(0.0133)$ & $(0.0155)$ & $(0.0566)$ & $(0.1839)$ \\
\hline \multirow[t]{2}{*}{ Average Temperature } & 0.0187 & 0.0353 & -0.0127 & 0.0106 & 0.0282 & -0.0465 \\
\hline & $(0.0141)$ & $(0.0223)$ & $(0.0420)$ & $(0.0181)$ & $(0.0234)$ & $(0.0457)$ \\
\hline \multirow[t]{2}{*}{ Minimum Temperature } & 0.0396 & 0.0323 & 0.0222 & 0.0429 & 0.0357 & 0.0608 \\
\hline & $(0.0274)$ & $(0.0355)$ & $(0.0353)$ & $(0.0287)$ & $(0.0372)$ & $(0.0710)$ \\
\hline \multirow[t]{2}{*}{ Maximum Temperature } & 0.0635 & 0.0542 & 0.0612 & 0.0616 & 0.0535 & 0.0645 \\
\hline & $(0.0195)^{* *}$ & $(0.0277)^{*}$ & $(0.0515)$ & $(0.0302)^{* *}$ & $(0.0311)^{*}$ & $(0.0333)^{* *}$ \\
\hline \multirow[t]{2}{*}{ Wind Speed } & -0.0465 & -0.0273 & -0.0184 & -0.0396 & -0.0306 & 0.0574 \\
\hline & $(0.0400)$ & $(0.0251)$ & $(0.0147)$ & $(0.0426)$ & $(0.0564)$ & $(0.0998)$ \\
\hline \multirow[t]{2}{*}{ Precipitation } & 0.1399 & 0.0112 & 0.1844 & 0.1291 & 0.1662 & -0.0805 \\
\hline & $(0.0623)^{* *}$ & $(0.0157)$ & $(0.1599)$ & $(0.0686)^{*}$ & $(0.0910)^{*}$ & $(0.1745)$ \\
\hline \multirow[t]{2}{*}{ Smoker (No) } & -0.0046 & -0.0062 & -0.0012 & -0.0041 & -0.0053 & -0.0033 \\
\hline & $(0.0042)$ & $(0.0045)$ & $(0.0020)$ & $(0.0037)$ & $(0.0048)$ & $(0.0021)$ \\
\hline \multirow[t]{2}{*}{ Household size } & -0.0436 & -0.0383 & -0.0128 & -0.0421 & -0.0032 & -0.0305 \\
\hline & $(0.0191)^{* *}$ & $(0.0223)^{*}$ & $(0.0273)$ & $(0.0199)^{* *}$ & $(0.0014)^{* *}$ & $(0.0711)$ \\
\hline \multicolumn{7}{|l|}{ Job Status (ref=self-employed) } \\
\hline \multirow[t]{2}{*}{ Job Status (Unemployed) } & 0.1018 & 0.1289 & 0.0104 & 0.1133 & 0.1234 & 0.5268 \\
\hline & $(0.1023)$ & $(0.1131)$ & $(0.1101)$ & $(0.1065)$ & $(0.1179)$ & $(0.4584)$ \\
\hline \multirow[t]{2}{*}{ Job Status (Employed) } & 0.0870 & 0.0870 & -0.4895 & 0.1255 & 0.1097 & -0.0223 \\
\hline & $(0.0790)$ & $(0.0859)$ & $(0.4396)$ & $(0.0828)$ & $(0.0899)$ & $(0.3823)$ \\
\hline \multirow[t]{2}{*}{ Job Status (Retired) } & 0.1225 & 0.1289 & 0.2041 & 0.1742 & 0.1234 & 0.301 \\
\hline & $(0.970)$ & $(0.1131)$ & $(0.6856)$ & $(0.1017)^{*}$ & $(0.1179)$ & $(0.166)^{*}$ \\
\hline \multicolumn{7}{|l|}{ Marital Status (ref=married) } \\
\hline \multirow{2}{*}{$\begin{array}{c}\text { Marital Status (Living as } \\
\text { couple) }\end{array}$} & -0.2230 & -0.3839 & 0.0239 & -0.3147 & -0.4469 & 0.0236 \\
\hline & $(0.3115)$ & $(0.3313)$ & $(0.0136) * * *$ & $(0.3160)$ & $(0.3371)$ & $(0.0137)^{* * *}$ \\
\hline Marital Status (Widowed) & 0.1083 & -0.2257 & 0.0235 & -0.1650 & -0.2560 & 0.0238 \\
\hline & $(0.3083)$ & $(0.3284)$ & $(0.0142)^{* * *}$ & $(0.3125)$ & $(0.3338)$ & $(0.0142)^{* * *}$ \\
\hline Marital Status (Divorced) & 0.0827 & -0.2154 & 0.0210 & -0.1734 & -0.2952 & 0.0219 \\
\hline & $(0.3291)$ & $(0.3491)$ & $(0.0137)^{* * *}$ & $(0.3348)$ & $(0.3561)$ & $(0.0139)^{* * *}$ \\
\hline Tenure (ref=owned outright) & & & & & & \\
\hline Tenure house & 0.0408 & 0.0126 & -0.3330 & 0.0557 & 0.0735 & -0.3180 \\
\hline (Owned with mortgage) & $(0.0547)$ & $(0.0251)$ & $(0.1935)$ & $(0.0565)$ & $(0.0610)$ & $(0.2039)$ \\
\hline Tenure house & 0.0551 & 0.1349 & -0.8153 & 0.0479 & 0.2730 & -0.6408 \\
\hline (Rented from Employer) & $(0.1928)$ & $(0.2768)$ & $(0.5285)$ & $(0.1981)$ & $(0.2585)$ & $(0.5401)$ \\
\hline Tenure house & 0.1335 & 0.3226 & -0.1324 & 0.2226 & 0.3733 & -0.1245 \\
\hline (Rented Private Unfurnished) & $(0.1001)^{*}$ & $(0.1405)^{* *}$ & $(0.3301)$ & $(0.1036)^{* *}$ & $(0.1442)^{* *}$ & $(0.3442)$ \\
\hline Education (ref=Higher degree) & & & & & & \\
\hline Education Level (First Degree) & -0.0789 & -0.0626 & 0.4760 & -0.0764 & -0.0139 & 0.5895 \\
\hline & $(0.2161)$ & $(0.2515)$ & $(0.9204)$ & $(0.2232)$ & $(0.2601)$ & $(0.9334)$ \\
\hline Education Level & 0.1612 & 0.2585 & 0.2377 & 0.1569 & 0.2289 & 0.2447 \\
\hline (Teaching, HNC) & $(0.2744)$ & $(0.3143)$ & $(0.1447)$ & $(0.2816)$ & $(0.3235)$ & $(0.1577)$ \\
\hline Education Level (A Level) & 0.0448 & 0.1974 & 0.2377 & 0.0405 & 0.1992 & 0.2216 \\
\hline & $(0.2332)$ & $(0.2699)$ & $(0.2019)$ & $(0.2420)$ & $(0.2797)$ & $(0.2042)$ \\
\hline No obs. & 49,873 & 42,171 & 2,648 & 46,207 & 39,017 & 2,534 \\
\hline LR chi-square & 760.63 & 734.70 & 437.12 & 759.81 & 727.77 & 456.39 \\
\hline & {$[0.000]$} & {$[0.000]$} & {$[0.000]$} & {$[0.000]$} & {$[0.000]$} & {$[0.000]$} \\
\hline MWTP & 0.0028 & 0.0029 & 0.0027 & 0.0018 & 0.0022 & 0.0015 \\
\hline $\begin{array}{l}\text { MWTP for a drop of one unit } \\
\text { per year }\end{array}$ & $£ 84$ & $£ 87$ & $£ 70$ & $£ 52$ & $£ 65$ & $£ 45$ \\
\hline
\end{tabular}

Standard errors between brackets, p-values between square brackets, ***,** and * indicate significance at $1 \%, 5 \%$ and $10 \%$ level

Columns (1) and (4) refer to the total sample of the BHPS, columns (2) and (5) refer only to the non-movers sample and columns (3) and (6) refer to the movers within Britain sample. Columns (1)-(3) refer to CO and columns (4)-(6) refer to $\mathrm{O}_{3}$. 
Table 4. Binary Logistic Regressions Fixed Effects for Chest and Breathing Health Problems

\begin{tabular}{|c|c|c|c|c|c|c|}
\hline Model & (1) & (2) & (3) & (4) & (5) & (6) \\
\hline & & $\mathrm{CO}$ & & & $\mathrm{O}_{3}$ & \\
\hline \multirow[t]{2}{*}{ Household Income } & -0.0292 & -0.0240 & -0.0597 & -0.0259 & -0.0226 & -0.0662 \\
\hline & $(0.0142)^{* *}$ & $(0.0114)^{* *}$ & $(0.0146) * * *$ & $(0.0120)^{* *}$ & $(0.0105)^{* *}$ & $(0.0152)^{* * *}$ \\
\hline \multirow[t]{2}{*}{ Air Pollutant } & 0.0516 & 0.0607 & 0.0191 & 0.0481 & 0.0576 & 0.0151 \\
\hline & $(0.0231)^{* *}$ & $(0.0265)^{* *}$ & $(0.0055)^{* * *}$ & $(0.0220)^{* *}$ & $(0.0239) * *$ & $(0.0065)^{* *}$ \\
\hline \multirow[t]{2}{*}{ Age } & 0.0161 & 0.0152 & 0.0170 & 0.0143 & 0.0136 & 0.0181 \\
\hline & $(0.0077)^{* *}$ & $(0.0078)^{* *}$ & $(0.0147)$ & $(0.0068)^{* *}$ & $(0.0065)^{* *}$ & $(0.0245)$ \\
\hline \multirow[t]{2}{*}{ Average Temperature } & -0.0261 & -0.0131 & 0.0381 & -0.0249 & -0.0215 & -0.0520 \\
\hline & $(0.0115)^{* *}$ & $(0.0071)^{*}$ & $(0.0508)$ & $(0.0122)^{* *}$ & $(0.0106)^{* *}$ & $(0.0621)$ \\
\hline \multirow[t]{2}{*}{ Minimum Temperature } & 0.0444 & 0.0701 & 0.1243 & 0.0360 & 0.0692 & 0.0118 \\
\hline & $(0.0363)$ & $(0.0464)$ & $(0.0963)$ & $(0.0287)$ & $(0.0496)$ & $(0.1078)$ \\
\hline \multirow[t]{2}{*}{ Maximum Temperature } & 0.0807 & 0.0907 & 0.1331 & 0.0788 & 0.0951 & 0.1471 \\
\hline & $(0.0427)^{*}$ & $(0.0507)^{*}$ & $(0.1018)$ & $(0.0413)^{*}$ & $(0.0537)^{*}$ & $(0.1102)$ \\
\hline \multirow[t]{2}{*}{ Wind Speed } & 0.0036 & 0.0097 & 0.0423 & 0.0093 & 0.1262 & 0.0477 \\
\hline & $(0.0537)$ & $(0.0329)$ & $(0.1460)$ & $(0.0465)$ & $(0.0742)^{*}$ & $(0.1478)$ \\
\hline \multirow[t]{2}{*}{ Precipitation } & 0.1173 & 0.1142 & 0.0778 & 0.1037 & 0.1253 & 0.0770 \\
\hline & $(0.0236) * * *$ & $(0.0571)^{* *}$ & $(0.2113)$ & $(0.0480)^{* *}$ & $(0.0612)^{* *}$ & $(0.2242)$ \\
\hline \multirow[t]{2}{*}{ Smoker (No) } & -0.0102 & -0.0129 & -0.0144 & -0.0101 & 0.0126 & -0.0083 \\
\hline & $(0.0053)^{*}$ & $(0.0058)^{* *}$ & $(0.0121)$ & $(0.0056)^{*}$ & $(0.0062)^{* *}$ & $(0.0188)$ \\
\hline \multirow[t]{2}{*}{ Household size } & -0.0436 & -0.0677 & -0.0109 & -0.0442 & -0.0666 & -0.0093 \\
\hline & $(0.0212)^{* *}$ & $(0.0257)^{* * *}$ & $(0.0059)^{*}$ & $(0.0215)^{* *}$ & $(0.0269)^{* *}$ & $(0.0048)^{*}$ \\
\hline \multicolumn{7}{|l|}{ Job Status (ref=self-employed) } \\
\hline \multirow[t]{2}{*}{ Job Status (Unemployed) } & 0.6481 & 0.4912 & 1.197 & 0.6121 & 0.4695 & 1.319 \\
\hline & $(0.1202)^{* * *}$ & $(0.1288)^{* * *}$ & $(0.5184)^{* *}$ & $(0.1211)^{* * *}$ & $(0.1341)^{* * *}$ & $(0.5864)^{* *}$ \\
\hline \multirow[t]{2}{*}{ Job Status (Employed) } & 0.0844 & 0.1383 & 0.9565 & 0.0870 & 0.1297 & 0.8755 \\
\hline & $(0.0885)$ & $(0.1029)$ & $(0.5195)^{*}$ & $(0.0881)$ & $(0.1068)$ & $(0.5132)^{*}$ \\
\hline \multirow[t]{2}{*}{ Job Status (Retired) } & 0.8339 & 0.7816 & 1.146 & 0.8253 & 0.7695 & 1.254 \\
\hline & $(0.1352) * * *$ & $(0.1174) * * *$ & $(0.0281)^{* * *}$ & $(0.1140) * * *$ & $(0.1341)^{* * *}$ & $(0.0294) * * *$ \\
\hline \multicolumn{7}{|l|}{ Marital Status (ref $=$ married) } \\
\hline \multirow{4}{*}{$\begin{array}{c}\text { Marital Status (Living as } \\
\text { couple) } \\
\text { Marital Status (Widowed) }\end{array}$} & -0.9226 & -0.8169 & -0.2145 & -0.9070 & -0.8771 & -0.2207 \\
\hline & $(0.7468)$ & $(0.7461)$ & $(0.0133) * * *$ & $(0.7165)$ & $(0.7470)$ & $(0.0128)^{* * *}$ \\
\hline & 0.7394 & 0.7127 & 0.2086 & 0.7263 & 0.7067 & 0.2150 \\
\hline & $(0.3447)^{* *}$ & $(0.3171)^{* *}$ & $(0.0121)^{* * *}$ & $(0.3123)^{* *}$ & $(0.2690)^{* *}$ & $(0.0124) * * *$ \\
\hline \multirow[t]{2}{*}{ Marital Status (Divorced) } & 0.7614 & 0.6138 & 0.2149 & 0.7143 & 0.6301 & 0.2245 \\
\hline & $(0.3608)^{* *}$ & $(0.2872)^{* *}$ & $(0.0139)^{* * *}$ & $(0.3287)^{* *}$ & $(0.2909) * *$ & $(0.0131)^{* * *}$ \\
\hline \multicolumn{7}{|l|}{ Tenure (ref=owned outright) } \\
\hline Tenure house & 0.0591 & 0.0337 & -0.2275 & 0.0348 & 0.0490 & -0.1792 \\
\hline (Owned with mortgage) & $(0.0601)$ & $(0.0657)$ & $(0.3359)$ & $(0.0635)$ & $(0.0682)$ & $(0.3800)$ \\
\hline Tenure house & 0.2077 & 0.2174 & 0.5066 & 0.1017 & 0.2497 & 0.5672 \\
\hline (Rented from Employer) & $(0.2536)$ & $(0.2852)$ & $(0.6665)$ & $(0.2446)$ & $(0.3065)$ & $(0.7540)$ \\
\hline Tenure house & 0.3170 & 0.2237 & 0.7321 & 0.2974 & 0.2162 & 0.8006 \\
\hline (Rented Private Unfurnished) & $(0.1443)^{* *}$ & $(0.1113)^{* *}$ & $(0.4010)^{*}$ & $(0.1473)^{* *}$ & $(0.1069)^{* *}$ & $(0.4621)^{*}$ \\
\hline Education (ref=Higher degree) & & & & & & \\
\hline Education Level (First & -0.0882 & -0.4554 & -0.1799 & -0.0759 & -0.5142 & -0.1687 \\
\hline Degree) & $(0.2561)$ & $(0.3502)$ & $(0.1684)$ & $(0.0544)$ & $(0.3659)$ & $(0.1384)$ \\
\hline Education Level & 0.2174 & 0.3036 & -0.1193 & 0.2795 & 0.5988 & -0.1072 \\
\hline (Teaching, HNC) & $(0.3211)$ & $(0.3747)$ & $(0.3209)$ & $(0.4064)$ & $(0.4366)$ & $(0.3167)$ \\
\hline Education Level (A Level) & 0.1942 & 0.4651 & 0.2752 & 0.1836 & 0.3300 & 0.2450 \\
\hline & $(0.2770)$ & $(0.4753)$ & $(0.2234)$ & $(0.2895)$ & $(0.3853)$ & $(0.2072)$ \\
\hline No obs. & 42,910 & 35,832 & 2,092 & 40,350 & 33,032 & 1,966 \\
\hline LR chi-square & $2,204.94$ & $2,177.09$ & 433.12 & $2,220.83$ & $2,146.17$ & 432.57 \\
\hline & {$[0.000]$} & {$[0.000]$} & {$[0.000]$} & {$[0.000]$} & {$[0.000]$} & {$[0.000]$} \\
\hline MWTP & 0.0062 & 0.0073 & 0.0026 & 0.0059 & 0.0070 & 0.0020 \\
\hline $\begin{array}{l}\text { MWTP for a drop of one unit } \\
\text { per year }\end{array}$ & $£ 185$ & $£ 218$ & $£ 84$ & $£ 173$ & $£ 208$ & $£ 60$ \\
\hline
\end{tabular}

Standard errors between brackets, p-values between square brackets, ***, ** and * indicate significance at $1 \%, 5 \%$ and $10 \%$ level

Columns (1) and (4) refer to the total sample of the BHPS, columns (2) and (5) refer only to the non-movers sample and columns (3) and (6) refer to the movers within Britain sample. Columns (1)-(3) refer to $\mathrm{CO}$ and columns (4)-(6) refer to $\mathrm{O}_{3}$ 
Table 5. Binary Logistic Regressions Fixed Effects for Heart Health Problems

\begin{tabular}{|c|c|c|c|c|c|c|}
\hline Model & (1) & (2) & (3) & (4) & (5) & (6) \\
\hline & & $\mathrm{CO}$ & & & $\mathrm{O}_{3}$ & \\
\hline \multirow[t]{2}{*}{ Household Income } & -0.0374 & -0.0340 & -0.0355 & -0.0333 & -0.0315 & -0.0429 \\
\hline & $(0.0168)^{* *}$ & $(0.0163)^{* *}$ & $(0.0172)^{* *}$ & $(0.0144)^{* *}$ & $(0.0142)^{* *}$ & $(0.0249)^{* *}$ \\
\hline \multirow[t]{2}{*}{ Air Pollutant } & 0.0605 & 0.0676 & 0.0459 & 0.0573 & 0.0601 & 0.0434 \\
\hline & $(0.0245)^{* *}$ & $(0.0381)^{* *}$ & $(0.0459)^{* *}$ & $(0.024)^{* *}$ & $(0.0279)^{* *}$ & $(0.0210)^{*}$ \\
\hline \multirow[t]{2}{*}{ Age } & 0.0187 & 0.0153 & 0.0190 & 0.0163 & 0.0138 & 0.0172 \\
\hline & $(0.0091)^{* *}$ & $(0.0072)^{* *}$ & $(0.0083)^{* *}$ & $(0.0076)^{* *}$ & $(0.0066)^{* *}$ & $(0.0082)^{* *}$ \\
\hline \multirow[t]{2}{*}{ Average Temperature } & -0.0441 & -0.0665 & 0.0381 & -0.0415 & -0.0621 & -0.1034 \\
\hline & $(0.0262)^{*}$ & $(0.0313)^{* *}$ & $(0.0608)$ & $(0.0224)^{*}$ & $(0.0296)^{* *}$ & $(0.1193)$ \\
\hline \multirow[t]{2}{*}{ Minimum Temperature } & 0.0811 & 0.0335 & 0.1243 & 0.0714 & 0.0349 & 0.1175 \\
\hline & $(0.0502)$ & $(0.0466)$ & $(0.0713)^{*}$ & $(0.0467)$ & $(0.0412)$ & $(0.0777)$ \\
\hline \multirow[t]{2}{*}{ Maximum Temperature } & 0.0781 & 0.0270 & 0.1334 & 0.0738 & 0.0276 & 0.1478 \\
\hline & $(0.0517)$ & $(0.0491)$ & $(0.1018)$ & $(0.0481)$ & $(0.0459)$ & $(0.1062)$ \\
\hline \multirow[t]{2}{*}{ Wind Speed } & -0.0455 & -0.0286 & 0.0323 & -0.0541 & -0.0333 & 0.0475 \\
\hline & $(0.0617)$ & $(0.0740)$ & $(0.0168)^{*}$ & $(0.0660)$ & $(0.0678)$ & $(0.1541)$ \\
\hline \multirow[t]{2}{*}{ Precipitation } & 0.2728 & 0.2990 & 0.0778 & 0.2779 & 0.3235 & 0.0734 \\
\hline & $(0.1232)^{* *}$ & $(0.1208)^{* *}$ & $(0.0613)$ & $(0.1294) * *$ & $(0.1300)^{* *}$ & $(0.0631)$ \\
\hline \multirow[t]{2}{*}{ Smoker (No) } & -0.0152 & -0.0177 & -0.0025 & -0.0143 & -0.0162 & -0.0040 \\
\hline & $(0.0060)^{* *}$ & $(0.0068)^{* *}$ & $(0.0049)$ & $(0.0062)^{* *}$ & $(0.0073)^{* *}$ & $(0.0111)$ \\
\hline \multirow[t]{2}{*}{ Household size } & -0.1492 & -0.1460 & -0.0304 & -0.1420 & -0.1339 & -0.0413 \\
\hline & $(0.0260)^{* * *}$ & $(0.0286) * * *$ & $(0.0176)^{*}$ & $(0.0275)^{* * *}$ & $(0.0302)^{* * *}$ & $(0.0233)^{*}$ \\
\hline \multicolumn{7}{|l|}{ Job Status (ref=self-employed) } \\
\hline \multirow[t]{2}{*}{ Job Status (Unemployed) } & 0.1516 & 0.1694 & 0.0104 & 0.1592 & 0.1598 & 0.0126 \\
\hline & $(0.1232)$ & $(0.0822)^{* *}$ & $(0.1101)$ & $(0.1282)$ & $(0.0792)^{* *}$ & $(0.1198)$ \\
\hline \multirow[t]{2}{*}{ Job Status (Employed) } & -0.1141 & -0.1117 & -0.0425 & -0.1101 & -0.1014 & -0.0416 \\
\hline & $(0.0920)$ & $(0.0979)$ & $(0.0884)$ & $(0.0960)$ & $(0.0822)$ & $(0.0835)$ \\
\hline \multirow[t]{2}{*}{ Job Status (Retired) } & 0.3499 & 0.2694 & 0.3422 & 0.2679 & 0.2831 & 0.3383 \\
\hline & $(0.0994) * * *$ & $(0.0942) * * *$ & $(0.1862)^{*}$ & $(0.1043) * * *$ & $(0.1105)^{* *}$ & $(0.1767)^{*}$ \\
\hline \multicolumn{7}{|l|}{ Marital Status (ref=married) } \\
\hline \multirow[t]{2}{*}{ Marital Status (Living as couple) } & -1.166 & -1.568 & 0.0676 & -0.9663 & -1.269 & 0.0643 \\
\hline & $(0.7462)$ & $(0.9011)$ & $(0.4455)$ & $(0.7419)$ & $(0.0799)$ & $(0.4787)$ \\
\hline \multirow[t]{2}{*}{ Marital Status (Widowed) } & 1.180 & 1.623 & 0.1063 & 1.040 & 1.380 & 0.1155 \\
\hline & $(0.7448)$ & $(0.0890)^{*}$ & $(0.4410)$ & $(0.0740)$ & $(0.0799)^{*}$ & $(0.4552)$ \\
\hline \multirow[t]{2}{*}{ Marital Status (Divorced) } & 1.513 & 1.965 & 0.0861 & 1.467 & 1.806 & 0.0821 \\
\hline & $(0.0750)^{* *}$ & $(0.0795)^{* *}$ & $(0.5211)$ & $(0.0726) * *$ & $(0.0845)^{* *}$ & $(0.5022)$ \\
\hline Tenure (ref=owned outright) & & & & & & \\
\hline Tenure house & -0.1363 & -0.1401 & 0.1406 & -0.1211 & -0.1261 & 0.1592 \\
\hline (Owned with mortgage) & $(0.0970)$ & $(0.0995)$ & $(0.0663)^{* *}$ & $(0.0997)$ & $(0.0863)$ & $(0.0684)^{* *}$ \\
\hline Tenure house & 0.2062 & 0.5223 & 0.1792 & 0.4230 & 0.5607 & 0.1601 \\
\hline (Rented from Employer) & $(0.2377)$ & $(0.3833)$ & $(0.0921)^{*}$ & $(0.2705)$ & $(0.3725)$ & $(0.0873)^{*}$ \\
\hline Tenure house & 0.4944 & 0.8147 & 0.1110 & 0.5224 & 0.8667 & 0.1014 \\
\hline (Rented Private Unfurnished) & $(0.1574)^{* * *}$ & $(0.2073) * * *$ & $(0.0675)$ & $(0.1662) * * *$ & $(0.2191)^{* * *}$ & $(0.0631)$ \\
\hline Education (ref=Higher degree) & & & & & & \\
\hline Education Level (First Degree) & 0.2071 & 0.2842 & 0.0362 & 0.1881 & 0.3257 & 0.0326 \\
\hline & $(0.5865)$ & $(0.6525)$ & $(0.1649)$ & $(0.6178)$ & $(0.6966)$ & $(0.1618)$ \\
\hline Education Level & -0.1088 & -0.0233 & 0.0883 & -0.1164 & -0.0180 & 0.0866 \\
\hline (Teaching, HNC) & $(0.6561)$ & $(0.0736)$ & $(0.2064)$ & $(0.6968)$ & $(0.0794)$ & $(0.1962)$ \\
\hline Education Level (A Level) & 1.169 & 1.456 & 0.0367 & 1.157 & 1.420 & 0.0351 \\
\hline & $(0.0610)^{*}$ & $(0.0686)^{* *}$ & $(0.1901)$ & $(0.0628)^{*}$ & $(0.0690)^{* *}$ & $(0.1894)$ \\
\hline No obs. & 50,397 & 43,582 & 1,640 & 47,324 & 40,553 & 1,575 \\
\hline LR chi-square & $3,566.73$ & $3,303.74$ & 226.63 & $3,707.01$ & $3,871.03$ & 215.44 \\
\hline & {$[0.000]$} & {$[0.000]$} & {$[0.000]$} & {$[0.000]$} & {$[0.000]$} & {$[0.000]$} \\
\hline MWTP & 0.0063 & 0.0075 & 0.0045 & 0.0060 & 0.0073 & 0.0045 \\
\hline $\begin{array}{l}\text { MWTP for a drop of one unit per } \\
\text { year }\end{array}$ & $£ 189$ & $£ 222$ & $£ 132$ & $£ 178$ & $£ 216$ & $£ 134$ \\
\hline
\end{tabular}

Standard errors between brackets, p-values between square brackets, ***, ** and * indicate significance at $1 \%, 5 \%$ and $10 \%$ level

Columns (1) and (4) refer to the total sample of the BHPS, columns (2) and (5) refer only to the non-movers sample and columns (3) and (6) refer to the movers within Britain sample. Columns (1)-(3) refer to $\mathrm{CO}$ and columns (4)-(6) refer to $\mathrm{O}_{3}$ 
Table 6. Dynamic Binary Probit Regressions for the Non-Movers Sample

\begin{tabular}{|c|c|c|c|c|c|c|}
\hline Model & $\begin{array}{c}\text { (1) } \\
\text { Skin } \\
\text { Conditions and } \\
\text { Allergy Health } \\
\text { Problems } \\
\end{array}$ & $\begin{array}{c}\quad(2) \\
\text { Chest and } \\
\text { Breathing } \\
\text { Health } \\
\text { Problems }\end{array}$ & $\begin{array}{c}(3) \\
\text { Heart Health } \\
\text { Problems }\end{array}$ & $\begin{array}{c}(4) \\
\text { Skin } \\
\text { Conditions and } \\
\text { Allergy Health } \\
\text { Problems }\end{array}$ & $\begin{array}{c}(5) \\
\text { Chest and } \\
\text { Breathing } \\
\text { Health } \\
\text { Problems }\end{array}$ & $\begin{array}{c}(6) \\
\text { Heart Health } \\
\text { Problems }\end{array}$ \\
\hline & & CO & & & $\mathrm{O}_{3}$ & \\
\hline Health Problem t-1 & $\begin{array}{c}-0.4823 \\
(0.0189) * * *\end{array}$ & $\begin{array}{c}-0.3562 \\
(0.0102)^{* * *}\end{array}$ & $\begin{array}{c}-0.3358 \\
(0.0117)^{* * *}\end{array}$ & $\begin{array}{c}-0.4827 \\
(0.0190)^{* * *}\end{array}$ & $\begin{array}{c}-0.3563 \\
(0.0102)^{* * *}\end{array}$ & $\begin{array}{c}-0.3347 \\
(0.0119)^{* * *}\end{array}$ \\
\hline Household Income & $\begin{array}{c}-0.0323 \\
(0.0153)^{* *}\end{array}$ & $\begin{array}{c}-0.0223 \\
(0.0104)^{* *}\end{array}$ & $\begin{array}{c}-0.0367 \\
(0.0125)^{* *}\end{array}$ & $\begin{array}{c}-0.0276 \\
(0.0123)^{* *}\end{array}$ & $\begin{array}{c}-0.0228 \\
(0.0107)^{* *}\end{array}$ & $\begin{array}{c}-0.0320 \\
(0.0153)^{* *}\end{array}$ \\
\hline Air Pollutant & $\begin{array}{c}0.0249 \\
(0.0117)^{* *}\end{array}$ & $\begin{array}{c}0.0597 \\
(0.0275)^{* *}\end{array}$ & $\begin{array}{c}0.0669 \\
(0.0452)^{* *}\end{array}$ & $\begin{array}{c}0.0198 \\
(0.0095)^{* *}\end{array}$ & $\begin{array}{c}0.0581 \\
(0.0267)^{* *}\end{array}$ & $\begin{array}{c}0.0595 \\
(0.0429)^{*}\end{array}$ \\
\hline No obs. & 36,918 & 29,853 & 37,212 & 33,081 & 27,135 & 34,891 \\
\hline Wald chi-square & $\begin{array}{c}3,313.00 \\
{[0.000]}\end{array}$ & $\begin{array}{c}7,367.16 \\
{[0.000]}\end{array}$ & $\begin{array}{c}8,966.28 \\
{[0.000]}\end{array}$ & $\begin{array}{c}3,639.98 \\
{[0.000]}\end{array}$ & $\begin{array}{c}7,053.24 \\
{[0.000]}\end{array}$ & $\begin{array}{c}8,757.71 \\
{[0.000]}\end{array}$ \\
\hline MWTP & 0.0025 & 0.0072 & 0.0073 & 0.0020 & 0.0068 & 0.0070 \\
\hline MWTP for a drop of one unit & $£ 76$ & $£ 215$ & $£ 218$ & $£ 60$ & $£ 203$ & $£ 208$ \\
\hline
\end{tabular}

Table 7. Number of Days In-patient in Hospital and Visits to SP Regressions for the Non-Movers Sample

Model DV: Number of Days Fixed Effects Regression

\begin{tabular}{ccccc}
\hline & $\begin{array}{c}\text { Chest-Breathing } \\
\text { Problems }\end{array}$ & Heart Problems & $\begin{array}{c}\text { Chest-Breathing } \\
\text { Problems }\end{array}$ & Heart Problems \\
\hline Household Income & -1.116 & -1.202 & -0.0258 & -0.0379 \\
Health Status (Poor) & $(0.454)^{* *}$ & $(0.566)^{* *}$ & $(0.0123)^{* *}$ & $(0.0182)^{* *}$ \\
& 1.515 & 1.832 & 1.669 & 2.178 \\
No obs. & $(0.717)^{* *}$ & $(0.818)^{* *}$ & $(0.4152)^{* * *}$ & $(0.3671)^{* * *}$ \\
R square & 19,454 & 19,454 & 31,619 & 42,979 \\
LR chi-square & 0.5963 & 0.5869 & & $3,689.24$ \\
& & & $3,501.12$ & {$[0.000]$} \\
\hline
\end{tabular}

Standard errors between brackets, p-values between square brackets. ***, ** and * indicate significance at 1\%, 5\% and 10\% level, Columns (1) and

(4) refer to total sample, (2) and (5) refer to non-movers and (3) and (6) refer to movers within GB 
Table 8. MWTP for Number of In-patient Days in Hospital, Visits in SP and Non-Movers Sample

Chest-Breathing Problems

Heart Problems

Panel A: Number of In-Patient Days in Hospital (£20 fee per night stay)

MWTP

MWTP for a unit drop

MWTP

MWTP for a unit drop

MWTP

MWTP for a unit drop

MWTP

MWTP for a unit drop

MWTP

MWTP for a unit drop

MWTP

MWTP for a unit drop
0.0050

$£ 155$

0.0048

$£ 147$

Panel B: Number of Visits in SP-Scenario 1 (3 hours)

$\mathrm{CO}$

0.0030

$£ 90$

0.0029

$£ 86$

$\mathrm{CO}$

0.0068

$£ 209$

$\mathrm{O}_{3}$

0.0058

$£ 180$

0.0044

$£ 131$

$\mathrm{O}_{3}$

0.0039

$£ 116$

Panel C: Number of Visits in SP-Scenario 2 ( $\$ 10$ monthly fee)

$\mathrm{CO}$

0.0048

$£ 150$

0.0046

$£ 142$
0.0059

$£ 182$

$\mathrm{O}_{3}$

0.0051

$£ 157$

\section{Endnotes}

i Department for Environment, Food and Rural Affairs (DEFRA), The Air Quality Strategy for England, Scotland, Wales and Northern Ireland, 2007

ii The analysis was also conducted using individual level income; however this is affected by labour force participation which we do not explicitly model here.

iii Haversine formula is:

First step: $\mathrm{R}=637100$ (the Earth's radius in meters)

Second step: $\Delta$ latitude $=$ latitude $_{1}-$ latitude $_{2}$

Third step: $\Delta$ longitude $=$ longitude $1-$ longitude $_{2}$

Fourth step: $\mathrm{a}=\sin ^{2}(\Delta$ latitude $/ 2)+\cos \left(\right.$ latitude $\left._{1}\right) \cdot \cos \left(\right.$ latitude $\left._{2}\right) \cdot \sin ^{2}(\Delta$ longitude $/ 2)$

Fifth step: $\mathrm{c}=2 \cdot \operatorname{atan} 2(\sqrt{\alpha}, \sqrt{1-\alpha}$

iv To test the sensitivity of this assumption, pollution levels using distance cutoffs of 5 and 15 kilometres have been also assigned and estimated as robustness tests similarly with the study by Currie and Neidell (2005). Additionally, separate regressions for weekly averages and one day lag of air pollution have been estimated. In all cases the results hold and are similar with the main results of the study; however are not presented. 